\title{
International regime complexes and corporate crime: a research agenda based on the Volkswagen diesel fraud
}

\section{case}

\section{Caelesta Braun ${ }^{1}$. Judith Van Erp ${ }^{2}$}

Accepted: 22 July 2021 / Published online: 8 September 2021

(c) The Author(s) 2021

\begin{abstract}
Criminological literature has often pointed to the absence or weakness of existing international regulation as important explanatory factors of corporate crime in global markets. This paper addresses the presence of multiple parallel, nested and overlapping regulatory regimes, and explores how such international regime complexity creates pathways to corporate crime. We use the Volkswagen diesel fraud case as a plausibility probe to illustrate such pathways to corporate crime. Our tentative analysis suggests that Volkswagen's fraud in the US cannot be seen as independent of the EU regulatory regime, which was more lenient and offered various opportunities for creative compliance. We conclude that a regime complexity perspective is a promising addition to existing explanations of corporate crime in international settings and suggest a research agenda for future in-depth analyses of the implications of parallel and conflicting regulatory regimes for corporate crime.
\end{abstract}

Keywords Corporate crime $\cdot$ International regime complexes $\cdot$ State-corporate crime $\cdot$ Global governance $\cdot$ Software fraud $\cdot$ Environmental crime

\section{Introduction}

The Volkswagen diesel fraud prominently features as a recent, far-reaching case of corporate crime. Volkswagen (VW) equipped its diesel cars with defeat devices, allowing for manipulation of nitrogen oxides (nox) emissions and, hence, lower

Judith Van Erp

j.g.vanerp@uu.nl

Caelesta Braun

c.h.j.m.braun@fgga.leidenuniv.nl

1 Institute for Public Administration, Faculty of Governance and Global Affairs, Leiden University, The Hague, The Netherlands

2 Utrecht School of Governance, Utrecht University, Utrecht, The Netherlands 
emission rates in tests, while effective in-use emissions were much higher than allowed. The fraud involved 11 million cars worldwide. Volkswagen's internal control systems, its culture; governance structure, and performance pressure are important factors in explaining the fraud [90, 100]. In addition, the press and other commentators have quickly pointed at the regulatory environment as a factor that significantly contributed to the fraud [33]. The Volkswagen (VW) Group, with 600.000 employees worldwide and factories in 27 countries, operated under a complex of multiple regulatory regimes, resulting in large differences in standards and enforcement in different jurisdictions. Volkswagens manufactured in Chattanooga, US have to conform to different standards and comply with different rules than similar diesel cars manufactured in VW's production facility in Wolfsburg, Germany. For example, installing defeat software devices is a criminal act in the US, whereas Volkswagen has suggested that under the EU regime, defeat devices were allowed $[33,42]$.

An international regulatory environment with multiple, partially overlapping and sometimes contradicting regimes is a common administrative environment for multinational corporations [24]. The diesel fraud raises the question how such regulatory complexes affect corporate crime. On the one hand, the VW case demonstrates how the existence of multiple regimes can increase opportunities for detection and can strengthen enforcement, as weaknesses in one regime can be compensated by another $[12,13]$. The diesel fraud was detected in the US whereas the effects of enforcement extend to the car manufacturing industry globally. On the other hand, the VW fraud raises the question whether the existence of multiple regulatory regimes may facilitate or create opportunities for corporate crime (cf [82]). In the VW case, we suggest that the more lenient EU regime could have created an environment conducive to manipulating software that may have reverberated when VW expanded its production to the more stringently regulated US context.

Both questions illustrate the relevance of taking the role of multilayered regulatory landscapes into account when studying corporate crime [20, 89, 105]. Although corporate criminologists have frequently studied the relation between globalization and corporate crime, they have done so mainly through the lens of the strategic exploitation of global regulatory gaps and loopholes by corporate actors $[45,70,81$, 101]. The current paper adds to this scholarship by developing a research agenda that shifts focus from the absence of rules, to the presence of a multilayered international regulatory complex and its implications for corporate crime.

The theory of international regime complexes is a promising avenue to explore such implications. Regime complex theory emerged from the notion that the complexity of international governance, which occurs via a multitude of nested, overlapping, and parallel trans-border agreements, affects outcomes within single regulatory regimes [5]. It proposes that behavior of individual actors within regulatory regimes should take into consideration that any single agreement is embedded in a larger web of international rules and regulations, which together form a complex system: a regime complex [5]. Inspired by complexity theory, Alter and Meunier argue that in complex systems, studying parts of the system without considering the full system, may lead to faulty understandings. Regime complexes often result in either rule ambiguity, fragmentation, institutional competition, or a combination 
thereof because their constituent regulatory regimes create multiple opportunities to achieve similar goals [11, 41]. International regime complexes are therefore likely to result in strategic behavior and/or unintended consequences when actors seek to navigate or exploit such multiple opportunities [11, 41, 46, 78, 83].

Regime complexity theory (RCT) has emerged from scholarship in international relations and has mainly focused on behavior of states in international regimes. Yet, Alter and Meunier [5], p. 22) recognized that regime complexity may also create strategic opportunities for non-state actors to influence outcomes. By building upon Alter and Meunier's [5] framework, we explore how regime complexes can evoke several pathways to corporate crime. By exploring the role of regime complexes in explanations of corporate crime, this paper aims to contribute to theories on the relation between globalization and corporate crime in two ways. First, we add to existing explanations of corporate crime in global settings by adding a more comprehensive perspective on how complex international regimes can induce corporate crime beyond the strategic exploitation of divergence and loopholes between individual regimes. Second, we advance regime complexity theory by investigating its applicability beyond states to corporations. By combining these two contributions we develop a research agenda for analyzing the effect of regime complexes on corporate crime.

We investigate the potential validity of regime complexes as explanation for corporate crime through a plausibility-probe case study of the Volkswagen case [26, 65]. Plausibility probes have been described as 'dipping a first toe in the empirical water' [23]. As such, they are often used to demonstrate the relevance of a theoretical proposition, as a step between hypothesis generation and hypothesis testing [65], when rigorous empirical testing is not feasible. As such, a plausibility probe fits the purpose of our paper, namely to develop a research agenda and assess the explanatory potential of regime complexity theory as framework for explaining corporate crime.

Our sources to document the case are publicly available documents, media accounts, and regulatory reports regarding the institutional and regulatory context in which the Volkswagen Diesel Fraud occurred, published between 2015 and 2017, the period of discovery and initial enforcement against Volkswagen. Focusing on the role of regime complexes necessarily means that our paper neither provides a full explanation of the causal mechanisms of the Volkswagen diesel fraud, nor of corporate crimes in general. Unidirectional causal claims are principally irreconcilable with the notion of complexity [5]. Moreover, corporate crimes always involve complex causal chains including individual, organizational, and political elements . We therefore confine our analysis to studying how the diesel emission regime complex may have induced the Volkswagen diesel fraud.

We proceed as follows. We first define international regime complexes and show how diesel emissions regulation constitutes such an international regime complex. We subsequently discuss how international regime complexes are likely to result in different pathways of corporate crime and illustrate these pathways with insights from the Volkswagen case. We find a plausible relation between the Volkswagen diesel fraud and the co-existence of multiple contrasting regulatory regimes and we conclude by pointing at the added value of a regime complexity perspective as 
analytical framework for understanding international corporate crime, and an agenda for future research.

\section{International regime complexes defined}

In today's globalized world, the authority for crafting and enforcing rules is shared between various public and private actors and decentralized in the sense that various regimes exist at different localities, often without central coordination (cf. [2, 50, 67, p. 1]). Interactions between individual regimes create intertwined institutional landscapes of nested, partially overlapping and parallel international regimes that are not hierarchically ordered [5], p. 13). These interwoven institutional landscapes are denoted as 'regime complexes' to indicate that regulatory institutions are not merely co-existing, but also interdependent [55]. A regime complex is defined as a complex of at least three regulatory regimes related to a common subject matter, exhibits overlapping membership, and generates substantive, normative, or operative interactions recognized as potentially problematic [78], p. 29, see also: [79]. International laws can be part of regime complexes in which they interact with other forms of regulation on the international plane.

International regime complexity is characterized by a lack of hierarchy, 'making it harder to resolve where political authority over an issue resides' [5]. Via multiple overlapping and parallel constituent regimes, regime complexity results in rule ambiguity and rule fragmentation: different rules apply within individual regimes of the complex. Different regimes constituting the complex may, for example, have conflicting core norms, provide different incentives and roles to actors, and hinder coordinated enforcement [91]. Corporate actors operating in a regime complex may face different regulatory demands and opportunities in different regimes, even to the extent that behavior defined as criminal in one regime, is lawful in another. Following Alter and Meunier [5] we identify four pathways to corporate crime. First, we discuss how regime complexes induce venue shopping which in turn facilitates corporate crime; second, how regime complexes create interactions between regimes, such as competition or reverberations between regimes, that might stimulate corporate crime. Third, we discuss how regime complexes generate small network environments which help legitimize corporate crime and, finally, how the complexity of international regimes result in cognitive biases that help normalize corporate crime.

\section{Diesel emissions regulations as an international regime complex}

The constellation of diesel emissions regulations in different jurisdictions across the globe is an example of a regime complex. In the US, the National Ambient Air Quality Standards (NAAQS) are currently regulated under EPA's Tier 2 and California LEV-II emissions regulations [18]. In the EU, Nox emissions standards are regulated under Euro standards. The complex of diesel emissions regulation in the car industry consists of parallel regulatory regimes for diesel emissions at the US and 
EU level, ${ }^{1}$ each with distinct regulatory goals and standards [76]. The centralized US regime was modeled after the Californian emission regulation and enforcement regime, which is, due to the lack of prominence of the car industry in the Californian political economy, one of the most stringent regimes in the world [102]. The EU regime, by contrast, consists of open norms and loose enforcement in a decentralized governance system based on different enforcement practices at the member-state level. Substantial differences exist in the laws regulating diesel emissions in cars between the EU and US [39, 76]. The most important differences between these regimes first regard the stringency of the norms (Although EU NOx emissions standards have tightened every year the US norm of $44 \mathrm{mg} / \mathrm{kg}$ is much stricter than the $80 \mathrm{mg} / \mathrm{kg}$ Euro 6 standard). Second, the US regime requires real-world testing, whereas the EU allows laboratory tests creating optimal artificial test circumstances [76]. In the US, the regulator more frequently tests (samples of) vehicles, whereas in the EU most of the testing is carried out by the manufacturer [53]. This is commonly assumed to explain why passenger cars in the EU technically comply with the ever more stringent emission standards, but this has not resulted in reduced real-world emission levels of cars produced in the EU. Third,'defeat devices' to circumvent emission control systems built in cars are explicitly defined and forbidden in the US Clean Air Act, which also limits exceptions to the use of these devices. Defeat devices are also forbidden in the EU since 2007 (act 5 of (EG) nr. 715/2007) but as the regulation does not specify what qualifies as an emission control system, nor specifies the exceptions in which defeat devices are allowed, there is more room for interpretations of the law that favor manufacturer's interests $[52,76]$. While the software used by Volkswagen in the US is unambiguously illegal under the US vehicle emissions regulations, it has been unclear whether this software was prohibited under the European Union regulation [51]. ${ }^{2}$ This difference in criminalizing corporate behaviour is illustrated by the varying penalties across the two regimes: Volkswagen has paid $\$ 25$ billion in penalties to the US government and nine of its executives have been indicted, one of whom has been imposed a prison sentence of seven years, whereas Germany was slow to reach a settlement with Volkswagen to pay a 1 billion euros administrative fine $[80,86]$ as well as with German prosecutors pressing charges against Volkswagen's CEO for grave cases of fraud as well as a breach of competition laws [7].

Although environmental organizations and some European states have since long lobbied for strengthening the EU diesel emissions regime towards a model like the US regime, there has been no coordination between the regimes. The regimes are at best characterized as 'loosely coupled'. The regime complex is international, rather

\footnotetext{
1 For the purposes of this paper, we exclude the Asian regulatory regime and focus on the regime complex composed of US, EU and global components.

2 In the oral and written testimony to the Transport Select Committee of Britain's House of Commons, the managing director of VW UK Paul Willis, and VW engineer Oliver Schmidt, have declared that EU regulations did not require manufacturers to declare software; that the EGR system is not part of the emissions control system as defined under EURO 5 standard, and that EU regulations do not prohibit a vehicle from recognizing when it is undergoing type approval. New regulations are under way addressing such weaknesses in the previous regulations and oversight systems (ECA 2019).
} 
than transnational, in the sense that most rules are legal rules set by states, nations, the EU and US separately, whereas overarching transnational regulation is largely absent (cf [2]. In addition to these parallel regimes, there is a clear multilayered aspect to the diesel emission regime complex. The structure of the EU regime is a multi-layered and nested regime, with authorities both at the EU and at member state level, combined with private certification agencies responsible for legislative decision-making as well as monitoring and enforcing compliance. Similarly, the US regime has a multilayered nature with a federal system with variation between state enforcement, with California as the most stringent state.

To conclude, the constellation of various diesel emissions regulations in the EU and US qualifies as a regime complex, which was defined as a complex of at least three regulatory regimes related to a common subject matter, exhibits overlapping membership; and generates substantive, normative, or operative interactions recognized as potentially problematic. We have identified two parallel regimes in the US and EU in combination with a multi-layered nested regime structure within the EU as well as among private regulators. We note that that the diesel emission regulation complex is relatively uncomplicated compared to other regimes complexes, as the constellation consists of two parallel and one nested regime, each with relatively straightforward rules. We have chosen a relatively simple case for our plausibility probe and provide suggestions for more complex cases in the research agenda. The following sections will demonstrate that even mild levels of complexity result in problematic interactions between regimes.

\section{International regime complexes and pathways to corporate crime in the Volkswagen Case}

The following sections discuss how the four pathways identified in international regime complex theory, may have been conducive to the Volkswagen diesel fraud.

\section{Pathway 1: how venue-shopping stimulates 'legal but harmful behavior'}

Regime complexity theory suggests that variation between international regimes provides actors with strategic opportunities for realization of their interests [5]. The most prominent mechanism via which actors can pursue strategic opportunities is venue-shopping $[10,58]$. Venueshopping allows actors to use or exploit horizontal variation between regulatory actors and opt for the interpretation of the rules most favorable to their interest $[55,82,95]$. Corporate venue shopping is facilitated by the ability of multinational corporations to organize and diversify their corporate structure, their outsourcing strategy to maximize the benefit of individual favorable regimes-strategic tax planning is an obvious example - and to gain political advantage by securing political influence and protection [82]. In criminology, venue shopping has been primarily interpreted as the outsourcing of damaging activities from the Global North to weak regulatory regimes in the Global South where harmful behavior is not criminalized in the legal sense or jurisdictions where they are 
less exposed to the risk of private legal actions [21, 101]. This may result in harmful behavior that is termed crime in one jurisdiction, but legal in another.

\section{Corporate crime and venue shopping in the Volkswagen case}

The US and EU legislative regimes do not allow for venue shopping between them-European-based car manufacturers producing or selling cars in the US, are obligated to comply to all aspects of US legislation without being able to choose a different venue for type approval. Venue shopping was possible however within the EU regime. In the EU, driving tests are standardized based on the New European Driving Cycle (NEDC), which include several sequences of test rides, carried out by private auditing companies and car manufacturers themselves with very limited after-sale testing [73]. Furthermore, compliance with emissions standards in the EU is monitored by national type approval authorities and based on mutual recognition: once a car is certified in one member state, it can circulate freely throughout the EU. This stimulates car manufacturers to seek out the most beneficial facilities to implement tests. Type approval is granted by the national authority in the country of manufacturing, based on test certificates of private auditing companies. Although driving tests are to a certain extent standardized on the basis of the New European Driving Cycle (NEDC), private auditing companies vary regarding the intensity of testing, and circumstances vary across test circuits [76]. In addition, car manufacturers can either opt for real-world or lab conditions-most prefer lab conditions where cars can be stripped from side mirrors, air conditioning, etc.

While the EU sets the legal framework, national authorities are fully responsible for monitoring car manufacturers' compliance, and no coordination of enforcement takes place. The EU refers to a 'standing obligation' of member states to police offenses, but in reality, member states have not investigated compliance, and car manufacturers strategically select test agencies to their advantage [76]. As Fiat Chrysler CEO Sergio Marchionne commented: "Bad rules are also applied in a different way in every country, creating the worst solution that could be invented" [87]. Thus, variation in enforcement between EU states and auditing companies weakened compliance-not to the letter, but to the spirit of EU emissions regulations. The nested nature of the EU regime offered opportunities for venue shopping within the EU regime, and thus explains how Volkswagen (and other car manufacturers) could cosmetically comply with emissions regulation and evade the increasingly stringent norms in the EU. This explanation fits with existing criminological accounts of corporate loophole-seeking behavior.

Volkswagen aspired to become the biggest car seller in the world, and the US small market for diesel cars offered enormous opportunities to expand sales. However, what was allowed in the EU, was strictly forbidden in the US. Defeat devices are unambiguously criminalized in the US. The US regime also emphasizes independent conformity testing much more than the EU and the EPA more frequently tests (samples of) vehicles, test results are public, and in-use testing is more common [18]. The EU and US regime can be characterized as parallel and irreconcilable regimes. Venue shopping between regimes was impossible. Parallel regimes imply 
that actors cannot choose between regimes, nor can they rely on compliance practices in one regime to comply in another. They need to develop different compliance behaviours for both regimes, which is costly, or comply with the more stringent regime if the regimes do not contradict each other. Here, regime complex theory sheds light on the influence of the architecture of the regime complex - in this case two parallel, formally independent and uncoordinated regimes-on opportunities and facilitating conditions for corporate crime. Venue shopping thus can only explain part of the conditions that led to the VW diesel fraud-the weak compliance in the EU-but more elaborate analysis is necessary to understand how the two regimes interacted, despite operating without coordination.

\section{Pathway 2: How interactions between regimes facilitate corporate crime}

The existence of multiple parallel and/or nested regimes is likely to generate interaction effects such as competition between regimes in the regime complex and reverberation of regulatory and compliance practices across regimes. In such situations, it is likely that a so-called 'elemental' (primary) regime develops which influences behavior in other regimes and creates unexpected outcomes [41]. For example, strong states may extend their shadow of hierarchy to weaker states through extraterritorial jurisdiction $[12,13]$. Different, parallel regimes can generate two opposite reactions from corporations. First, the most stringent regulatory regime could function as the elemental regime, shaping behavior of corporations in other, less stringent regimes. Thus, more stringent regimes have spillover effects, and can cast an external shadow of hierarchy $[12,13]$ when corporations voluntarily adopt the more stringent rules even in areas with less stringent regimes. Such spillover can occur when corporations see efficiency gain in standardization of practices in different geographic areas or reputational gain in beyond-compliance behavior in the more lenient regime [22], p. 29). Powerful global actors can even impose regulatory standards to other states to close gaps between regimes, such as happened when US law enforcement authorities pressurized Switzerland to adapt tax secrecy laws, under the threat of criminal prosecution of Switzerland's largest bank [28]. Over time, productive interactions between regimes within a regime complex can also occur, such as information exchange,learning from experiences of other regulatory bodies or mutual adjustment $[2,79,99]$. States now make more efforts to coordinate enforcement against transnational corporate crimes, by sharing evidence and joint prosecution, such as happened when the US and Germany collaborated in the prosecution of Siemens for transnational bribery [108].

On the other hand, interaction effects may invite a "race to the bottom", strategic exploitation of regulatory diversity to further an actor's self-interest [62, 79]. Criminologists have often demonstrated how regulatory ambiguity creates opportunities for loophole seeking behavior, creative or strategic compliance, evading responsibility in complex global production chains, and denying or neutralizing damage [15, $45,81]$. For example, differences in excise duties imposed on cigarettes in different countries have been exploited by tobacco companies complicit with cigarette smuggling by local criminal networks [21]. The fact that corporate behavior is perceived 
as economically productive and is politically supported in one regime, provides corporations justifications for offenses in other regimes. Thus, more lenient regimes may serve as elemental institutions and undermine commitment to more stringent regimes or provide a cognitive framework neutralizing crime (cf. [9].

Not only regulated actors, but also states may exploit or sustain differences in regimes to protect important domestic industries [8, 74]. The support for and assistance with corporate tax avoidance of various European states is an obvious example where states such as Switzerland, the Netherlands and Ireland actively resist EU and US attempts to ban corporate tax rulings [28]. Similarly, attempts to coordinate international environmental treaties governing the same subject area, such as climate change, maritime or air pollution, have proven politically unfeasible in regard of the existing interests of stakeholders benefiting from regulatory voids [103]. These examples illustrate that close relations between states and industries or corporations can explain the continuation of regime complexes despite attempts to coordinate.

\section{Competition, reverberation and corporate crime in the Volkswagen case}

Does the notion of competition and reverberation between the more stringent US and the more lenient EU regime add to the explanation of the VW diesel fraud? The VW case provides two instances of positive spillover, in which the more stringent US regulatory regime positively reverberated to the EU. First, the fraud was discovered by coincidence when the International Council for Clean Transportation commissioned a report with West Virginia University [94], that detected elevated oxides of nitrogen (NOx) emissions in real world driving conditions. The ICCT commissioned the tests as part of their lobbying efforts to demonstrate that the more stringent US regulatory regime was more effective in reducing real-world emissions. It expected that such evidence could be used to convince the EC to support more stringent testing - in other words the competition between the regimes motivated the research. The ICCT report subsequently triggered the CARB and EPA to engage in further real-world testing of Volkswagen cars, eventually detecting the fraud [18].

Second, the detection of the eventually served as a window of opportunity for regulatory entrepreneurs in the parallel EU regime. In January 2016, the EC released new legislative proposals for a testing programme similar to the US [85] with more independent testing, ex-post testing of cars in circulation (Real Driving Emissions), access to software protocols and financial penalties for noncompliance [30]. Here, the parallel US regime provided a model for the EU.

The RCT lens also points to the question why the productive dynamics associated with competing regimes were entirely absent in the EU diesel emissions testing practice before the fraud was discovered in the US. The ambiguous EU norms reflect deep and unresolvable conflicts between social goals of economic prosperity realized through corporate profits, and environmental sustainability realized through regulation of diesel emissions. Compliance with emission standards confronted diesel car manufacturers with severe technological design problems, as a tradeoff exists between fast ignition and emissions control. In view of Volkswagen's aspiration to become the biggest seller of cars in the world, a driving experience fueled by speedy 
and sports-like accelerations was perceived as a necessity-but this is exactly what emissions control prevents [18]. Volkswagen is generally viewed to lack technological innovative capacity and was termed 'the dinosaur' long before the diesel fraud $[33,44]$.

Because of the lenient monitoring and audit regime in Europe, 'cosmetic' compliance could be realized there without fundamental innovations to diesel engines. It can thus be argued that the possibility to shop for favorable certificates of compliance in the EU undermined innovation of the car industry necessary for legal compliance in the much more stringent US regulatory regime, and rendered the EU regime the elemental regime, de facto overshadowing the US regime.

Interaction effects within the Diesel emission complex mainly consisted of reverberation of more stringent US norms in the detection of the fraud and offering legislative opportunities for the EU system to adopt stricter regulation and compliance as well. At the same time, the leniency of the EU regime seems to have rendered it the de facto elemental regime within the complex. Both positive and negative) interactions between regimes in a regime complex regime are important to consider for understanding how corporate crime develops or is prevented. At the same time, strategic venue shopping (pathway 1) or interaction effects between the individual regimes (pathway 2) leave questions open why Volkswagen expanded production to the US without adapting to the more stringent US rules.

\section{Pathway 3: Small network environments and neutralization of corporate crime}

The complexity of international regimes multiplies the number of institutional venues, while at the same time reducing the number of policy makers with sufficient expertise. They also increase the occasions where these key players meet and negotiate. As a result, regulation and implementation effectively become the responsibility of a small group of institutional representatives in closed networks often subject to small group dynamics. Such small-network environments create a beneficial environment to negotiate international agreements based on trust, yet they also pose challenges associated with small-group dynamics [5], 18-19). Complex regulatory environments may increase the desire of both regulated actors and local regulators to clarify, coordinate and negotiate the application and interpretation of rules and the meaning of compliance in local contexts [72, 92]. This creates a certain familiarity or reduced relational distance (cf. [62] between corporate and state actors at the expense of external accountability and transparency [37, 38, 72]. The resulting close relationships could encourage corporate actors into more faithful compliance $[57,59]$, but may also develop into collusive relationships where trust becomes a more important feature of the interactions than regulatory compliance (cf. [16, 98]). Group dynamics may induce state actors to overly identify with private actors' interests and develop shared social-economic goals, which would be hampered by aggressive regulation or enforcement practices [19]. In small-network dynamics, horizontal and mutually reinforcing interactions between political and economic institutions may facilitate corporate crime when state regulatory institutions fail to restrain deviant business activities. 


\section{Small networks and neutralization of corporate crime in the Volkswagen case}

Relations between Volkswagen and the German state have historically been close [33]. Volkswagen's corporate governance structure is typical for Germany and known as co-determination, in which the state is a major shareholder and representation of the labor force is significant [27]. The state of Lower Saxony holds almost $13 \%$ of the shares and the Lower Saxony's prime minister is a formal member of the supervising board, with veto power over VW's strategic decisions. Governors of Lower Saxony serve as directors at Volkswagen,several of them have subsequently become the German Chancellor (Gerhard Schröder) or vice Chancellor (Sigmar Gabriel) [27]. So, the nexus between the company and the German state and the federal government is very tight. Traditionally, Lower Saxony has used its powers to encourage creating and maintaining jobs within the state, resulting in high labor costs [27] [68]. More than 20\% of VW's worldwide labor force work at its headquarters in Wolfsburg and four other plants in Lower Saxony [36]. Relations between the German government and Volkswagen Group constitute a closed network with a strong level of trust and familiarity based on a shared interest in sustaining the German car industry and employment [33]. The Volkswagen Group and the German federal state formed a strong tandem lobbying for maintaining the industry-friendly status quo and watering down proposals for more stringent, environmentally friendly EU regulations [33, 47].

How has this network created a pathway for the diesel fraud? There are no indications that German political actors knew about the defeat devices. However, the deep connection between German politics and Volkswagen and the open acknowledgement of the strong dependence of the German economy on the Volkswagen's performance, combined with intense political lobbying for lenient EU regulation, may have provided a justification for Volkswagen's cosmetic compliance with EU emission rules. However, the close relations that VW maintained to the German government were entirely absent in the US. The relational distance between political and regulatory bodies and Volkswagen was very large in the US and Volkswagen could not exploit a position of trust to ensure a favorable interpretation of the rules. Volkswagen's interests were however put forward to US regulators as the German government lobbied for more lenient regulation in the US, even to the point that Chancellor Merkel herself bilaterally negotiated with the Californian Governor on emission regulations.

In line with scholarship on state corporate crime, we argue that the contribution of the institutional environment to crime is not a direct causal effect, but a 'contributing precedent'. Collusive corporate-state relations, with close relations between the corporate actors committing crimes and the political elite authorizing it, create 'a political culture and organizational frameworks that ultimately led to heinous acts that would not have occurred without that culture and those frameworks' [70, p. 206]. A close network of political and corporate actors based on a long historical tradition in the German political economy and the larger relational distance in the US help explain why the Volkswagen fraud could exist for a prolonged period of time in the EU, yet was detected and prosecuted in the US within a relatively short period of time after the start of production. The Volkswagen case illustrates how 
such networks affect incentives for reforms, the conditions under which such closed networks result in corporate crime or could yield more positive corporate outcomes. Precisely because the type and quality of interactions within such networks (such as trustworthiness or familiarity) might also explain commitment to more sustainable and good corporate governance goals instead of corporate crime, multi-directional effects of these networks are important to consider.

\section{Pathway 4: How regime complexity induces cognitive biases}

Related to the group dynamics associated with (small) networks, cognitive biases are characteristic of decision-making within regime complexes. As regime complexes are characterized by many different regulations, norms and enforcement practices, information overload for both decision-makers and non-state actors frequently occurs in regime complexes [5]. Scholars of complexity and policymaking often have observed that complexity and information overload result in bounded rationality as actors attempt to cope with these circumstances. As a result decision-making is often characterized by heuristics and cognitive biases [56], a reality shown to characterize complex regulation and regulatory regimes as well [62, 67]. Such heuristics may result in a neglect of systemic risks, such as happened for example during the financial crisis [1,106]. Also, they may facilitate strategic framing of an issue favorable to particular (corporate) interests [14, 61]. The presentation of tax rulings and tax havens as beneficial to a national economy is, again, an obvious example, just as the framing of environmental damage caused by extractive industries as a 'local issue'.

Biases not only characterize corporate decision-making in such a complex environment but are also demonstrated to apply to public officials. Criminologists have observed cognitive biases in enforcement against reputable corporate actors, as well as collective cultural beliefs in the superiority of a corporation; its innovative entrepreneurship; technical competency, to act as a smoke screen. In various cases, such as the Enron accounting fraud [88], Madoff investment fraud (Van de Bunt [97], Siemens corruption case [60],); and Deepwater Horizon spill [72], these biases explain how corporate actors are placed beyond doubt despite obvious signals of fraud or misbehaviour. Such concerted ignorance is seen as characteristic of collusive corporate-state relations contributing to corporate crime.

\section{Cognitive biases and corporate crime in the Volkswagen case}

Cognitive biases can be observed in the Volkswagen diesel fraud case both on the side of Volkswagen, and on the side of EU enforcement. First, although there is no doubt that Volkswagen knew defeat devices were forbidden in the US [33], Volkswagen clearly underestimated the severity of criminal sanctions and administrative penalties and liability claims it would face in the US [54]. Its ignorance regarding external reactions resembles Ford's unresponsiveness in the notorious Ford Pinto case, where Ford took the calculated risk of placing an unsafe fuel tank [63]. Volkswagen apparently realized it had limited understanding of the US 
legal system as it asked a US law firm for an estimation of the potential regulatory fines for defeat devices. The assumption that corporations make rational calculations of the risk of deterrence is already commonly questioned in corporate criminology-it is likely that risk assessment is even more obfuscated when corporations operate in different jurisdictions. This is supported by the fact that the first VW manager who has been convicted in the US, notified the FBI of his vacation plans to the US- apparently without worrying that he would be arrested and, eventually imprisoned for seven years, as happened [80]. Similarly, it is unlikely that Volkswagen's CEO Winterkorn took the calculated risk of being criminally prosecuted in the US.

Although there is certainly an element of calculated risk-taking in the Volkswagen diesel fraud, the regime complexity lens points to the cognitive deficiencies that can arise out of operating in another jurisdiction such as unawareness of the unlawfulness of behavior; a lack of insider awareness, more limited lobbying power compared to domestic companies; and a lack of cultural awareness of the timing, appropriateness and tone of deference to authorities [77]. Entering a new regime requires socialization, not only becoming familiar with the letter of the law but also into regulatory culture and reading between the lines. In the Volkswagen case, particularly the latter seems to have been the case, as Volkswagen denied and covered up the installation of defeat devices after the EPA made inquiries [54, 100].

Complexity-related cognitive biases can also be recognized in the fundamental differences in interpretation of diesel emissions violations between the EU and US regulatory and enforcement authorities. It was commonly assumed in the EU that the discrepancy between real world and lab emission results should be attributed to the lack of implementation of technical emissions reduction systems. Diesel emissions were interpreted as a regulatory problem, not as a compliance problem. European reports, press releases and statements refer to pending new legislation requiring real world and technically superior emission tests, the struggle to implement it, and the discussion regarding its supposed effectiveness. It seems that the possibility of fraud was not considered in Europe in a similar way as it was in the US, where regulators were well aware of the possibility of defeat devices, and several manufacturers had been prosecuted [18].

Illustrative in this regard, is that the European Commission's Joint Research Centre was already suspicious that large gaps between on-road and in-lab emission tests were caused by defeat devices [104, p. 36]. JRC's representatives testified before the European Parliament's diesel enquiry committee after the discovery of the diesel fraud that they never investigated whether car makers were using illegal software as that would have been beyond their research mandate (EU [29]. The chair of the European Parliament's diesel enquiry Kathleen van Brent dubbed the situation an "astonishing collective blindness to the defeat device issue in the European commission, as well as in other EU institutions" (The [93]. EU officials have stated anonymously that fear of manipulation of tests was common among technical officials, but 'attempts to act on those fears never gained much traction in a highly politicised commission environment' [35].

In addition, the conflicting goals of profitmaking and environmental compliance may generate subtle cognitive messages regarding the relative moral importance 
attached to these goals, which can form cognitive maps that govern managers' moral assessments of their choices such that they may not recognize anything wrong, even if their choices violate law [40, 107]. In the Volkswagen case, the shared corporate-political belief in the economic benefits of Volkswagen for the European, and in particular the German, economy, coupled with the solely symbolic restraints on economic profitmaking, may have created a situation of institutional anomie: a tolerance for corporate rule-breaking, weak support for the law and a lack of counterbalance to economic profitmaking as 'this is how business works' [81]. Situations of anomie result in fuzzy lines between legitimate and illegitimate behavior and allow corporate actors to neutralize their acts by denying criminality or neutralizing damage by appealing to 'higher' loyalties such as Volkswagen's importance to the German economy and blaming the regulatory state [9, 64]. In line with criminological scholarship, the ambivalence of 'clean diesel' in itself, the absence of identifiable victims; and the invisibility of damage contribute to ambiguity of offenses [75].

Pathway 4 regarding modes of decision-making in regime complexes indeed adds to the explanation of the Volkswagen Fraud. It seems plausible that Volkswagen, based on its experience in the more lenient EU/German regime did not fully acknowledge the differences between the EU and US regimes. Different interpretations of environmental harms of diesel emissions between the two regimes as a regulatory versus enforcement issue; conflicting goals of corporate profitmaking vs environmental compliance and VW's status in the EU may likely have contributed to biased decision-making resulting in the diesel fraud. These observations yield questions with regard to the kind of biases in corporate and political decision-making arising in regime complexes, the conditions that either reinforce or alleviate these biases, and, importantly, how to prevent or remedy their impact.

\section{Summary: how the diesel emission complex yielded multiple pathways for the Volkswagen Fraud}

Overall, our analytical framework of pathways to corporate crime in complex regimes demonstrates how industry-friendly emissions regulation in the EU and acceptance of loophole seeking by European car manufacturers within the EU, provided strategic opportunities for creative compliance of Volkswagen in the EU, allowing it to comply symbolically without actually reducing diesel emissions. Open norms in the EU also facilitated venue shopping within the EU to find the most favorable test location and seemed to have stalled innovations necessary to obtain truly lower levels of Nox emissions. All this may have caused the enabling and supportive institutional context for behavior that was deemed 'cosmetic compliance' in the EU but interpreted as straightforward fraud in the US. Our analysis suggests that the permissive EU regime functioned as elemental regime in the international regime complex, and reverberated in the US context, rendering Volkswagen unresponsive to the more stringent US regime. Rather than US regulation casting its shadow over manufacturing decisions in Europe, we suggest that the ambiguity of the EU regulatory regime created a culture within Volkswagen in which manipulation of emissions and cosmetic compliance were normalized. We argue that it is 
plausible that this not only influenced Volkswagen's behavior in the EU, but also its non-compliance with US regulation. Its closeness to EU authorities, the shared corporate-political beliefs about the industry's and Volkwagens position in the German and EU political-economy resulted in a certain status of Volkswagen, biased decision-making and hence blind spots for corporate fraud, and eventually, an underestimation of both the stringency of the US regime and the likelihood and severity of prosecution. In addition, we observed that the interaction between the regimes within the regime complex eventually facilitated the detection of the fraud and subsequent regulatory adaptations to curb creative compliance in the EU. Put differently, an international regime complexity perspective demonstrates that behavior of actors in one regulatory regime, cannot be understood without analyzing the influence of parallel regimes on its corporate activity and decision-making.

\section{Regimes complexes and corporate crime: towards a research agenda}

Explanations of corporate crime usually involve the relevance of individual characteristics, organizational structure and culture, market circumstances, and the economic, social and normative institutional environment, including legal frameworks and enforcement. Globalization impacts many of these explanations. Criminological theories thus far have mainly explored the absence and weakness of regulation in a global context and the implications thereof for corporate crime, mainly through strategic venue shopping and loophole seeking behavior. A regime complexity perspective not only draws attention to these implications of global regulatory regimes. It also points at the relevance of more broadly assessing interactions within a regime complex such as reverberation of regulatory practices and competition between institutions, the impact of small political-corporate networks in international governance, and, finally, the group dynamics and modes of decision-making associated with such networks to explain why and how corporate crime arises and can be sustained.

Drawing a relation between regime complexes and corporate crime has important implications for regulatory and enforcement policy. Policy makers and regulatory authorities operating in complex regimes, as well as corporate compliance officials and lawyers, could be more aware of the crime-facilitating nature of regime complexes. The analytical lens developed in this paper also supports attempts for regulatory coordination, collaboration and information exchange between regulators.

More research is necessary to strengthen the theoretical and empirical foundation of regime complexity theory applications to corporate crime. Our plausibility probe of the Volkswagen case does suggest that a regime complexity perspective yields a fruitful research agenda investigating the relation between regime complexes and corporate crime. We outline several relevant aspects to consider for such a research agenda. First, our analysis indicates the importance of the interplay between the individual regimes, such as reverberation of regulatory practices (both positive or negative) or institutional competition for ultimate regulatory authority. While we could not unequivocally ascertain whether the EU regulatory regime functioned as elemental regime in the Diesel complex, thus de facto overpowering 
US regulatory norms, such a pathway is certainly plausible and helpful to explain the Volkswagen fraud. More definitive explanations of interaction effects within a regime complex require detailed information on how regulatory practices and rules induce competition in other parts of the regime complex, how exactly they reverberate within the complex, and how that affects corporate and political coordination (cf. [83]. Whereas the VW case is a configuration of a lenient EU versus a stringent US constellation, future research could address other configurations. The recent GDPR regulations for privacy and data protection, for instance, are an example of EU regulations and enforcement practices being more stringent in comparison to their US counterparts, yet it remains to be seen whether reverberation will arise within the regime complex. At the same time, organized crime infiltration in business (RICO Act), competition regulation [49], or banking secrecy [28] are examples of global regulatory issues in which the US regime is the more stringent one and for which enforcement results in de facto global convergence of regulated practices. On the other hand, the expansion of the extraterritorial jurisdiction of states against organized and corporate crimes, in particular by the US through the Foreign Corrupt Practices Act and RICO (Racketeering Influenced and Corrupt Organizations) Act, have been found to decrease the opportunities for jurisdiction shopping by extending US law enforcement to actors outside the US [108].

Second, our analysis indicates the importance of considering both the constellation and functioning of public-private networks within an international governance context. Regime complexity is assumed to yield relatively small networks of corporate-political actors [5] and our plausibility probe indeed indicates the relevance of such networks to explain corporate behavior. So, a more comprehensive understanding of how such networks arise and affect corporate and political behavior (cf. [96] and public-private regulatory collaboration [3] should constitute an important pillar of a research agenda on how regime complexity affects corporate behavior. Future research could address interactions between public and private regimes, for example CSR standards that serve as overlapping regimes with sometimes higher-reaching legal or private norms and sometimes regulatory logics that differ from public legislation.

Third, our analysis adds to existing criminological explanations of corporate crime as exploitation of regulatory loopholes, by drawing attention to the constellations between regimes and the architecture of their relations. Parallel, conflicting, or nested regimes may create different types of loopholes, but also more complex interactions - so the nature of the relation matters. We have noted that the diesel emission regime complex is a relatively straightforward complex with parallel rather than conflicting rules. Even for such relatively straightforward regime complexes, our analysis suggests the added value of a regime complexity perspective. Future research should add to our understanding of how regime complexes induce varieties of corporate behavior by adopting a comparative approach. This is in line with existing research demonstrating the effect of variation among regulatory domains and regimes to explain corporate political behavior [17, 48]. Comparing regimes with varying levels of complexity, such as international tax evasion or money laundering, helps to ascertain how different levels of complexity induce more or less 
competition or how they affect the constellation and decision-making modes of international regulatory networks.

Finally, and in line with our earlier observations that unidirectional causal claims are irreconcilable with the notion of complexity, our framework suggests the need for more explicitly considering the interdependent nature of the individual pathways. For instance, the closeness of Volkswagen to German and EU public officials points at the existence of a small network that yielded biased decision-making: it plausibly led to underestimation of the legal risks resulting from expanding fraudulous behavior to a more stringent regime. The pathways (small networks and biased decision-making) are not only interrelated, theoretically they could also yield different outcomes under different circumstances. Our framework and case study point to the importance of more explicitly considering the co-variational nature of regime complexes and corporate behavior in future research.

Acknowledgements The authors thank participants at Compliancenet; European Society of Criminology, and ECPR Regulatory Governance conferences, as well as reviewers of this paper for valuable remarks on earlier versions of this article.

Funding Caelesta Braun acknowledges financial support by the Dutch Research Council (Nederlandse Organisatie voor Wetenschappelijk Onderzoek (NWO)), grant no. 452-14-012.

Open Access This article is licensed under a Creative Commons Attribution 4.0 International License, which permits use, sharing, adaptation, distribution and reproduction in any medium or format, as long as you give appropriate credit to the original author(s) and the source, provide a link to the Creative Commons licence, and indicate if changes were made. The images or other third party material in this article are included in the article's Creative Commons licence, unless indicated otherwise in a credit line to the material. If material is not included in the article's Creative Commons licence and your intended use is not permitted by statutory regulation or exceeds the permitted use, you will need to obtain permission directly from the copyright holder. To view a copy of this licence, visit http://creativecommons.org/licen ses/by/4.0/.

\section{References}

1. Aalbers, A. M., Engelen, E., \& Glasmacher, A. (2011). Cognitive closure in The Netherlands: Mortgage securitization in a hybrid European political economy. Environment and Planning, 43, 1779-1795.

2. Abbott, K. (2011). The transnational regime complex for climate change. Environment and Planning C: Government and Policy, 30, 571-590.

3. Abbott, K. W., Levi-Faur, D., \& Snidal, D. (2017). Theorizing regulatory intermediaries, the RIT model. The Annals of the Academy of Political and Social Science, 670(1), 14-35.

4. Aizenberg, E. (2021), 'Lobbying alone. A study of political access and lobbying behavior of corporations in Western Europe', Amsterdam: University of Amsterdam Press.

5. Alter, K. J., \& Meunier, S. (2009). The politics of international regime complexity. Perspectives on Politics, 7(1), 13-24.

6. Aubert, . (1952). White-collar crime and social structure. American Journal of Sociology, 58(3), 263-271.

7. Amelang, S., A Whermann, B. (2019). "Dieselgate"-A timeline of the car emissions fraud scandal in Germany. Clean Energy Wire, 5 September 2019. Available at : https://www.cleanenerg ywire.org/factsheets/dieselgate-timeline-car-emissions-fraud-scandal-germany. 
8. Bach, D., \& Newman, A. (2014). Domestic drivers of transgovernmental regulatory cooperation. Regulation and Governance, 8(4), 395-417.

9. Benson, M. L. (1985). 'Denying the guilty mind: Accounting for involvement in white-collar crime. Criminology, 23, 583607.

10. Bernhagen, P., \& Mitchell, N. (2009). The determinants of direct corporate lobbying in the European Union. European Union Politics, 10(02), 155-176.

11. Betts, A. (2013). Regime complexity and international organizations: UNHCR as a challenged institution. Global Governance, 19, 69-81.

12. Börzel, T. A., \& Risse, T. (2010). Governance without a state: Can it work? Regulation and Governance, 2010.

13. Börzel, T. A., \& Risse, T. (2015). Dysfunctional state institutions, trust, and governance in areas of limited statehood, Regulation and Governance, 2015.

14. Boräng, F., \& Naurin, D. (2015). 'Try to see it my way!' Frame congruence between lobbyists and European Commission officials. Journal of European Public Policy, 22(4), 499-515.

15. Braithwaite, J., \& Drahos, P. (2000). Global business regulation. Cambridge University Press.

16. Braun, C. (2013). The driving forces ofstability. Exploring the nature of long-term bureaucracyinterest groupinteractions. Administration and Society, 45(7), 809-836. https://doi.org/10.1177/ 0095399712438377.

17. Braun, C., Albareda, A., Fraussen, B., \&Müller, M. (2020). Bandwagons and quiet corners in regulatory governance. Onregulation-specific and institutional drivers of stakeholder engagement. InternationalReview of Public Policy, 2(2), 209-232. https://doi.org/10.4000/irpp.1151.

18. Canis, B., Lattanzio, R., Vann, A., \& Yaccobucci, B. (2016). Volkswagen, defeat devices, and the Clean Air Act: Frequently asked questions. Congressional Research Service Report 7-5700. https:// fas.org/sgp/crs/misc/R44372.pdf.

19. Carpenter, D. P., \& Moss, D. A. (Eds.). (2014). Preventing regulatory capture: Special interest influence and how to limit it. Cambridge University Press.

20. Coen, D., \& Pegram, T. (2015). Wanted: A third generation of global governance research. Commentary. Governance, 28, 417-420.

21. Croall, H. (2005). Transnational white collar crime. In Sheptycki, J., \& Wardak, A. (eds), Transnational and comparative criminology, Routledge (pp. 227-247).

22. Davis, C. L. (2009). Overlapping institutions in trade policy. Perspectives on Politics, 27(1), 25-31.

23. Drezner, D. W. (2009). The power and peril of international regime complexity. Perspectives on Politics, 27(1), 65-70.

24. Eberlein, B., Abbott, K. W., Black, J., Meidinger, E., \& Wood, S. (2014). Transnational business governance. Regulation and Governance, 8, 1-21.

25. European Court of Auditors (ECA). (2019). The EU's response to the "Dieselgate" Scandal. Briefing paper, available at: https://www.eca.europa.eu/lists/ecadocuments/brp_vehicle_emissions/brp_ vehicle_emissions_en.pdf.

26. Eckstein, H. (1992). Regarding politics: Essays on political theory, stability, and change. Berkeley: University of California Press.

27. Elson, C., Ferrere, C., \& Goossen, N. (2015). The bug at Volkswagen: Lessons inco-determination, ownership, and board structure. Journal of AppliedCorporate Finance, $27,4$.

28. Emmenegger, P. (2017). Swiss banking secrecy and the problem of international cooperation in tax matters: A nut too hard to crack? Regulation and Governance, 11, 24-40.

29. EU Observer. (2016). EU science body did not suspect diesel cheating, 20 April 2016, Brussels, via: https://euobserver.com/environment/133127.

30. European Commission (EC). (2016). European Commission tightens rules for safer and cleaner cars, press release European Commission, 27 January 2016.

31. European Commission Joint Research Centre. (2013). A complementary emissions test for lightduty vehicles: Assessing the technical feasibility of candidate procedures, Technical report by Joint Research Centre European Commission.

32. EP report. (2016). Draft Report on the Inquiry into emission measurements in the automotive sector (2016/2215(INI)). European Parliament 2014-2019.

33. Ewing, J. (2017). Faster, higher, farther, the inside story of the Volkswagen Scandal. London: Bantam Press.

34. Ewing, J. (2018). "Ex-Volkswagen C.E.O. charged with fraud over diesel emission", New York Times, May 2018, available at : https://www.nytimes.com/2018/05/03/business/volkswagen-ceodiesel-fraud.html. 
35. Financial Times. (2015). Volkswagen emissions scandal exposes EU regulatory failures, September 30 2015. http://www.ft.com/intl/cms/s/0/03cdb23a-6758-11e5-a57f-21b88f7d973f.html.

36. Fortune. (2016). Hoaxwagen. How the massive diesel fraud incinerated VW's reputation-and will hobble the company for years to come, 7 March 2016, via: http://fortune.com/inside-volkswagenemissions-scandal/.

37. Fraussen, B. (2013). The visible hand of the state: On the organizational development of interest groups. Public Administration, 92(2), 406-421.

38. Fraussen, B., Beyers, J. ,\& Donas, T. (2014). 'The expanding core and varying degrees of insiderness: Institutionalised interest group access to advisory councils. Political Studies.

39. Frigessi di Rattalma M. (ed) (2017). The Dieselgate: A legal perspective. Springer.

40. Gaim, M., Clegg, S., \& Pina e Cunha, M. (2019). Managing impressions rather than emissions: Volkswagen and the false mastery of paradox. Organization Studies.

41. Gehring, T., \& Faude, B. (2013). The dynamics of regime complexes: Microfoundations and systemic effects. Global Governance, 19, 133-130.

42. German, J. (2017). Why are EU manufacturers claiming their defeat devices are not defeat devices?, ICCT Blog 10-2-2017, via https://www.theicct.org/blogs/staff/why-are-eu-automakersclaiming-defeat-devices-are-not-defeat-devices. Accessed December 202017.

43. Geuss, M. (2015). Volkswagen's emissions cheating scandal has a long, complicated history, Arstechnica 10/8/2015 http://arstechnica.com/cars/2015/10/volkswagens-emissions-cheating-scand al-has-a-long-complicated-history/.

44. Gouldson, A. (1993). Fine tuning the dinosaur? Environmental product innovation and strategic threat in the automotive industry: A case study of the Volkswagen Audi Group. Business Strategy and the Environment, 2, 12-21.

45. Grabosky, P. (2009). Globalisation and white collar crime. In Simpson, S., \& Weisburd, D. (eds). The criminology of white collar crime. Springer (pp. 129-151).

46. Green, J., \& Auld, G. (2016). Unbundling the regime complex: The effects of private authority. Transnational Environmental Law, Available on CJO 2016.

47. Gulbrandsen, L. H., \& Christensen, A. R. (2014). EU legislation to reduce car emissions. Review of Policy Research, 31, 503-528.

48. Hanegraaff, M., \& Berkhout, J. (2019). More business as usual? Explaining business bias across issues and institutions in the European Union. Journal of European Public Policy, 26(6), 843-862.

49. Harding, C. (2006). Business collusion as a criminological phenomenon: Exploring the global criminalisation of business cartels. Critical Criminology, 14, 181-205.

50. Hooghe, L., \& Marks, G. (2003). Unraveling the Central State, but how? Types of multi-level governance. American Political Science Review, 97(2), 233-243.

51. ICCT. (2016a). Briefing 'Defeat devices under the US and EU passenger vehicle emissions testing regulations', March 2016.

52. ICCT. (2016b). Review of LDV OBD requirements under the European, Korean and Californian emission programs, White paper.

53. ICCT. (2015a). Position Brief 'Policy Solutions to reduce vehicle exhaust emissions under realworld driving conditions', October 2015.

54. Jacobs, D., \& Kalders, L. (2019). The Volkswagen diesel emissions scandal and accountability. Where were the auditors and attorneys during the sustainability charade? The CPA Journal, 16-21.

55. Jensen, M. D., Koop, C., \& Tatham, M. (2014). Coping with power dispersion? Autonomy, coordination, and control in multi-level systems. Journal of European Public Policy, 21(9), 1237-1254.

56. Jones, B. D. (2003). Bounded rationality and political science: Lessons from public administration and public policy. Journal of Public Administration Research and Theory, 13(4), 395-412.

57. Kagan, R., Gunningham, N., \& Thornton D. (2011). Fear, duty, and regulatory compliance:Lessons from three research projects. In V. Nielsen, \& C. Parker (Eds.), Explainingregulatory compliance (pp. 37-58). Edward Elgar, UK.

58. Keck, M. E., \& Sikkink, K. (1999). Transnational advocacy networks in international and regional politics. ISSJ, 1, 59 .

59. Kim, Y., \& Darnall, N. (2016). Business as collaborative partner: Understanding firm's sociopolitical support for policy formation. Public Administration Review, 76(2), 326-337.

60. Klinkhammer, J. (2015). 'Varieties of corruption in the shadow of Siemens. A modus-operandi study of corporate crime on the supply side of corrupt transactions'. In: Van Erp, J., Huisman, W., \& Vande Walle, G. (eds), The Routledge handbook of white-collar and corporate crime in Europe. Routledge (pp. 318-335). 
61. Klüver, H., Mahoney, C., \& Opper, M. (2015). Framing in context: How interest groups employ framing to lobby the European Commission. Journal of European Public Policy, 22(4), 481-498.

62. Koop, C., \& Lodge, M. (2014). Exploring co-ordination of economic regulation. Journal of European Public Policy, 21(9), 1311-1329.

63. Lee, M., \& Ermann, D. (2001). Pinto madness: Flaws in the generally accepted landmark narrative. In Ermann, D., \& Lundman, R. (eds), Corporate and governmental deviance. Problems of organizational behavior in contemporary society. Oxford University Press.

64. Leeper Piquero, N., Tibbetts, S., \& Blankenship, M. (2005). Examining the role of differential association and techniques of neutralization in explaining corporate crime. Deviant Behavior, 26(2), 159-188.

65. Levy, J. (2008). Case studies: Types, designs, and logics of inference. Conflict Management and Peace Science, 25, 1-18.

66. Marshall, D., \& Bernhagen, P. (2017). Government-business relations in multilevel systems: The effect of conflict perception on venue choice. West European Politics, 40(5), 981-1003.

67. Mathieu,E.,Verhoest, K., \& Matthys, J. (2017). Measuring multi-level regulatory governance: Organizationalproliferation, coordination, and concentration of influence. Regulation\& Governance, 11, 252-268. https://doi.org/10.1111/rego.12127.

68. Merenda, J., \& Irwin, M. (2018). Case study: Volkswagen's diesel emissions control scandal. Journal of Strategic Innovation and Sustainability, 13(1), 53-62.

69. Messner, S., \& Rosenfeld, R. (2007). Crime and the American dream. Wadsworth Cengage Learning, Belmont CA.

70. Michalowski, R., \& Kramer, R. C. (1987). The space between the laws: The problem of corporate crime in a transnational context. Social Problems, 34, 34-53.

71. MichalowskiR., \& Kramer R., (2007). State-corporate crime and criminological inquiry. In H. Pontell \& G. Geis (Eds.), International handbook of white-collar andcorporate crime (pp. 200-219). Springer.

72. Mills, R. W., \& Koliba, C. J. (2015). The challenge of accountability in complex regulatory networks: The case of the Deepwater Horizon oil spill. Regulation and Governance, 9, 77-91.

73. Mock, P., \& German, J. (2015). The future of vehicle emissions testing and compliance. How to align regulatory requirements, customer expectations, and environmental performance in the European Union. ICCT, via https://www.theicct.org/sites/default/files/publications/ICCT future-vehicle-testing_20151123.pdf.

74. Mügge, D., \& Stellinga, B. (2010). Absent alternatives and insider interests in postcrisis financial reform. Der Moderne Staat: Zeitschrift für Public Policy, Recht und Management, 3(2), 321-338.

75. Nelken, D. (2012). 'White collar and corporate crime'. In Maguire, M., Morgan, R., \& Reiner, R. (eds) The Oxford handbook of criminology. Oxford University Press.

76. Nesbit, M., Ferguson, N., Colsa, A., Ohlendorf, J., Hayes, C., Paquel, K., \& Schweitzer, J. (2016). Comparative study on the differences between the EU and US legislation on emissions in the automotive sector, Study for the European Parliament Directorate General for Internal Policies, IP/A/EMIS/2016-02, PE 587.331.

77. New York Times (NY Times). (2015). Volkswagen faces harsher penalities than a U.S. Company might, 28 September 2015, via: https://www.nytimes.com/2015/09/29/business/dealbook/ volkswagen-faces-harsher-penalties-than-a-us-company-might.html.

78. Orsini, A., Morin, J., \& Young, O. (2013). Regime complexes: A buzz, a boom, or a boost for global governance? Global Governance: A Review of Multilateralism and International Organizations, 19(1), 27-39.

79. Overdevest, C., \& Zeitlin, J. (2014). Assembling an experimentalist regime. Transnational governance interactions in the forest sector. Regulation and Governance, 8(1), 22-48.

80. Parloff, R. (2018). How VW Paid \$25 Billion for 'Dieselgate' - and Got Off Easy, Fortune, 6 February 2018, via http://fortune.com/2018/02/06/volkswagen-vw-emissions-scandal-penal ties/. Accessed July 152018.

81. Passas, N. (1990). Anomie and corporate deviance. Contemporary Crises, 14, 157-178.

82. Puig, S. (2014). International regime complexity and economic law enforcement. Journal of International Economic Law, 17(3), 491-516.

83. Quaglia, L., \& Spendzharova, A. (2021). 'Regime complexity and managing financial data streams: The orchestration of trade reporting for derivatives. Regulation and Governance. https://doi.org/10.1111/rego.12377 
84. Reuters. (2016a). China launches new AIIB development bank as power balance shifts, via: https://www.reuters.com/article/us-asia-aiib-investment/china-launches-new-aiib-developmentbank-as-power-balance-shifts-idUSKCN0UU03Y, accessed December 20 2017).

85. Reuters. (2016b). EU seeks more powers over national car regulations after VW scandal, via https://www.reuters.com/article/us-volkswagen-emissions-eu-regulations/eu-seeks-more-powers-over-national-car-regulations-after-vw-scandal-idUSKCN0V51IO.

86. Reuters. (2017a). Volkswagen pleads guilty in U.S. court in diesel emissions scandal, business news, via: https://www.reuters.com/article/us-volkswagen-emissions-idUSKBN16H1W4.

87. Reuters. (2017b). Fiat Chrysler CEO complains about emissions rules 'mess' in Europe, Business News, via https://www.reuters.com/article/us-fiatchrysler-emissions-ceo/fiat-chrysler-ceo-compl ains-about-emissions-rules-mess-in-europe-idUSKBN15O2OL.

88. Rosoff, S. (2007). The role of the mass media in the Enron Fraud: Cause or cure? In Geis, G., \& Pontell, H. (eds), International handbook of white-collar and corporate crime, Springer (pp. 513-523).

89. Ruggie, J. G. (2017). Multinationals as global institution: Power, authority and relative autonomy. Regulation and Governance 2017.

90. Spapens, A. (2018). The "Dieselgate" scandal: A criminological perspective. In A. C. M. Spapens, R. D. White, D. P. van Uhm, \& W. Huisman (Eds.), Green crimes and dirty money (pp. 91-112). Routledge.

91. Struett, M., Nance, M., \& Armstrong, D. (2013). Navigating the maritime piracy regime complex. Global Governance, 19, 93-104.

92. Talesh, S. (2015). Rule-Intermediaries in action: How state and business stakeholders influence the meaning of consumer rights in regulatory governance arrangements. Law and Policy, 37, 1-31.

93. The Guardian. (2016). European Commission warned of car emission test cheating devices five year before VW Scandal, 20 June 2016, via: https://www.theguardian.com/environment/2016/jun/ 20/european-commission-warned-car-maker-suspected-cheating-five-years-vw-scandal.

94. Thompson, G., Carder, D., Besch, C., Thiruvengadam, A., \& Kappanna, H. (2014). In-use emissions testing of light-duty diesel vehicles in the United States, Center for Alternative Fuels, Engines and Emissions.

95. Urpelainen, J. (2012). Unilateral influence on international bureaucrats: An international delegation problem. Journal of Conflict Resolution, 65(4), 704-735.

96. Van der Heijden, M., \& Schalk, J. (2019). Network relationships and standard adoption: Diffusion effects in transnational regulatory networks. Public Administration. https://doi.org/10.1111/padm. 12627

97. Van de Bunt, H. (2010). Walls of secrecy and silence. The Madoff case and cartels in the construction industry. Criminology and Public Policy, 9(3), 435-453.

98. VanErp, J. G., \& Huisman, W. (2017). Corporatecrime.In Al. Brisman, E. Carrabine, \& N. South (Eds.), The Routledge companion tocriminological theory and concepts. Routledge.

99. VanErp, J., Faure, M., Nollkaemper, A., \& Philipsen, N. (Eds.) (2019). Smart mixes for transboundaryenvironmental harm. CambridgeUniversity Press.

100. Van Rooij, B., \& Fine, A. (2018). 'Toxic corporate culture: Assessing organizational processes of deviancy'. Administrative Science 8 (23).

101. van Wingerde, C. G. (2015). 'The limits of environmental regulation in a globalized economy. Lessons from the Probo Koala case'. In van Erp, J. G., \& Huisman, W. (eds.). Routledge handbook of white-collar and corporate crime in Europe. Routledge.

102. Vogel, D. (2018). California Greenin': How the golden state became an environmental leader. Princeton University Press.

103. Von Moltke, K. (2011). On clustering international environmental agreements. In G. Winter (Ed.), Multilevel governance of global environmental change, sociology and the law (pp. 409-429). Cambridge University Press.

104. Weiss, M., Bonnel P., Hummel R., \& Steininger N. (2013). A complementary emissions test for light-duty vehicles: Assessing the technical feasibility of candidate procedures. Publications Office of the European Union. https://publications.jrc.ec.europa.eu/repository/handle/JRC75998.

105. Wilks, S. (2013). The political power of the business corporation. Edward Elgar.

106. Will, S., Handelman S., \& Brotherton D. (2012). How they got away with it. White collar criminals and the financial meltdown. Columbia University Press. 
107. Yeager, P. (2007). Understanding corporate lawbreaking: From profit seeking to law breaking. In H. Pontell, \& G. Geis (Eds.), International handbook of white-collar and corporate crime, (pp. 25-49). Springer.

108. Zagaris, B. (2015). International white collar crime: Cases and materials. Cambridge University Press.

Publisher's Note Springer Nature remains neutral with regard to jurisdictional claims in published maps and institutional affiliations. 